\title{
THE EFFICIENCY OF PUBLIC HEALTH AND MEDICAL CARE SYSTEMS IN EU COUNTRIES: DYNAMIC NETWORK DATA ENVELOPMENT ANALYSIS
}

\author{
Kristína Kočišová ${ }^{1}$, Jakub Sopko ${ }^{1}$ \\ ${ }^{1}$ Department of Banking and Investment, Faculty of Economics, Technical University of Košice, Nemcovej 32, \\ 04001 Košice, Slovak Republic
}

Link to this article: https://doi.org/10.11118/actaun202068020383

Received: 22. 2. 2019, Accepted: 31. 3. 2020

To cite this article: KOČIŠOVÁ KRISTÍNA, SOPKO JAKUB. 2020. The Efficiency of Public Health and Medical Care Systems in EU Countries: Dynamic Network Data Envelopment Analysis. Acta Universitatis Agriculturae et Silviculturae Mendelianae Brunensis, 68(2): 383-394.

\begin{abstract}
Our paper analyses the technical efficiency and the change in the efficiency of the healthcare systems in 23 European Union (EU) countries between 2008 and 2016 based on the data published by OECD. We apply Dynamic Network Data Envelopment Analysis (DNDEA) to assess the efficiency of the medical care system and public health system, together with overall healthcare system efficiency. The findings suggest that the efficiency of public health systems in 2016 were higher than the efficiency of medical care systems in the same year only in Denmark. In the case of France, Hungary, Ireland, Lithuania, Poland, Portugal, Spain and the United Kingdom, the medical systems were more efficient. The model marked Austria, Czech Republic, Estonia, Finland, Germany, Greece, Italy, Latvia, Luxembourg, Netherlands, Slovak Republic, Slovenia and Sweden as efficient in terms of the medical care system as well as the public health system in 2016.
\end{abstract}

Keywords: health, data envelopment analysis, DNDEA, European Union, efficiency

\section{INTRODUCTION}

The process of creating the different sectors of the national economy is influenced by changes that take place in this period. At present, the national economy includes four economic sectors: the primary, secondary, tertiary and quaternary. Between them, the tertiary sector can be considered as one of the fastest-growing and also the most critical sector of the national economy. The tertiary sector, also referred to as a service sector, includes all sectors of human activity, which are mostly related to the provision of services, in particular labour, knowledge, finance, infrastructure, products or combinations thereof. The relevant areas of the tertiary sector are health and education. The level of education and the adequate health status of the population affect the development of the country. Modern public healthcare monitors the satisfaction of the primary health needs of the population in providing quality and effective healthcare. The efficiency of the health system is becoming a much-debated area due to the rapid ageing of the population. We need to assess the efficiency of the country's health system across the full spectrum of demographic, socio-economic and political determinants, including globalisation processes.

At present, the role of efficiency monitoring and evaluation is mostly taken up by multinational organisations (e.g. WHO, OECD, Eurostat). They analyse the quality and availability of health services, fair financing and the investments that are made in this field. Each country aims to improve the targets set in the healthcare sector with an emphasis 
on adequate funding in accessible ways. Healthcare is one of the areas of the public sector, where more financial resources do not automatically mean better results or improvement of the health condition of the population.

Various methods of efficiency evaluation can be found in the literature, for example, ratio analysis, parametric approach, and non-parametric approach. The ratio analysis approach is the easiest way to calculate performance, but its limitation is that it provides information only on the relationship between one input and one output. The parametric approach can involve multiple inputs and outputs, and can also account for noise using an error term. It requires a pre-specified production function due to its parametric formulation. Within the parametric methods, the Stochastic frontier analysis (SFA) can be found. One of the limitations of SFA is that it requires specification of functional form and specification of a distributional form for the inefficiency term. Also, the non-parametric approach allows involving multiple inputs and outputs. Data envelopment analysis (DEA) is a nonparametric technique using a linear programming model that develops a single efficiency score for each observation. We can use DEA to measure technical efficiency, scale efficiency, allocative efficiency, congestion efficiency, and total factor productivity change.

In the last years, the authors prefer to use the DEA for evaluation of efficiency in the service sector. Debreau and Arrow (1954) and Farell (1957) have provided a basic concept for DEA models and presented the score of technical efficiency. The further development of this method was provided by Charnes et al. (1978), who introduced the CCR (Charnes, Cooper, Rhodes) model based on the assumption of constant returns to scale. Then Banker et al. (1984) developed the BCC (Bankers, Charnes, Cooper) model based on the assumption of variable returns to the scale. According to Charnes et al. (1978), DEA deals with efficiency evaluation of a set of decision-making units (DMUs) with homogenous structures. The traditional DEA concept relates to the efficiency analysis over a single period and assumes that efficiency is constant over this period. However, in many applications, we can take into account the changes in efficiency over time. Therefore, Färe et al. (1994) formulated the Malmquist productivity index to evaluate the changes in the efficiency of a set of DMUs over several consecutive periods. The disadvantage of the Malmquist index is the assumption that there are no intermediate links between two consecutive periods. In many real-world applications, however, intermediate links exist. Therefore classical models were extended by the dynamic DEA models. Zhu and Cook (2007) pointed to the fact that in many cases, the efficiency in sub-divisions connected to the form of the network can influence the overall efficiency of DMU. That is why they presented the network DEA model, which able us to study the process that usually remains hidden within the traditional DEA models, but only for a single period. To eliminate shortcomings of dynamic and network model, Ozcan and Khushalani (2017) presented the dynamic network DEA model (DNDEA). The DNDEA extends the network DEA model by computing absolute efficiency and changes in sub-divisions and overall efficiency over multiple periods. It can calculate the overall efficiency, and efficiency for each sub-division, based on long-term optimisation using carry-over variables which are permanently intermediate links from one to the other period.

In this study, we assess the efficiency of healthcare systems in 23 European Union countries between 2008 and 2016, based on data obtained from the OECD database using the DNDEA model. The efficiency of public health and medical care sub-division influences the quality of healthcare systems within analysed countries. To achieve the aim, we organise the paper as follow. In section 2, we provide a review of the relevant literature. We describe the methodology in section 3 , and section 4 presents data, main findings and results.

\section{Literature Review}

According to Cantor and Poh (2018), DEA is widely used to evaluate the efficiency of healthcare units and provides benchmarks for inefficient units to improve. DEA has many benefits that make it an attractive tool for assessing healthcare efficiency. Among the benefits we can include, for example, the ability:

- to assume the deterministic relationship between healthcare unit's resources (input) and health outcomes (outputs) (Grosskopf and Valdmanis, 1993),

- to work with multiple inputs and outputs at the same time without the need for strong assumptions about the functional form connecting the inputs with the outputs (Osei et al., 2005; Dyson and Shale, 2010),

- to compare with a peer or partner combinations simultaneously, which measures efficiency in relative rather than absolute terms (Pilyavsky and Staat, 2008),

- and to perform in the absence of price information (Morita, 2003)

Despite the DEA's benefits, several studies have highlighted some theoretical and methodological limitations that restrict the achievement of a right view of healthcare efficiency. For example, Adler and Yazhemsky (2010) discussed the sensitivity of the method to the selection of input and output. Than Ramírez-Valdivia et al. (2011) pointed to an inability to explain the variation in the efficiency score. Kneip et al. (2008) underlined the loss of discriminatory power as units and variables increase. Furthermore, Kousmanen (2009) mentioned the inability to perform efficiency evaluation with missing data. 
Major of studies use traditional radial DEA models, in particular, CCR and BCC model, were to achieve the efficiency, either a proportional input reduction or output expansion was needed. For example, Retzlaff-Roberts et al. (2004), Adang and Borm (2007), Ramírez-Valdivia et al. (2011), Hadad et al. (2013), Medeiros and Schwierz (2015), Samut and Cafri (2016) applied the basic model to evaluate efficiency in OECD countries, and EU countries. In the condition of the Czech Republic and Slovakia we can find the application of the basic DEA models in study of Grausová et al. (2014), Grausová et al. (2015), Vaňková and Vrabková (2014), Sendek et al. (2015), Stefko et al. (2016), Staňková and Papadaki (2017).

Retzlaff-Roberts et al. (2004) analysed the technical efficiency in OECD countries in 1998. They want to identify which countries were utilising their healthcare inputs in a technically efficient manner, given the level of health outcomes and taking into account the environmental challenges of each country. They found out that many of the technically efficient countries such as Sweden and Japan had good health outcomes. However, several countries with moderate health outcomes (e.g. Mexico, and Turkey), were found to be efficient as well, suggesting that a country can be efficient in the use of its health resources and yet in urgent need of improvement in health outcomes. On the other hand, some of the inefficient countries (e.g. Hungary), had poor health outcomes and a high potential for improvement. In contrast, others, (e.g. Switzerland) had good outcomes but were utilising resources inefficiently. Thus they found that a country can be efficient in the use of its resources at any level of health outcomes.

Adang and Borm (2007) explored the association between the economic performance of healthcare and public satisfaction with healthcare systems in $15 \mathrm{EU}$ countries during the period 1995-2000. They used the output-oriented DEA model under the assumption of constant returns to scale and the change in productivity over time measured by the Malmquist productivity index. They found out that improving the economic performance of health systems may not necessarily improve citizens' satisfaction with those health systems.

Grausová et al. (2014) examined healthcare system efficiency in the Visegrad group during the period 2004-2010 based on non-radial Slacks-Based Measure model. They calculated super efficiency score to rank countries and to suggest improvements for the Visegrad group, and Malmquist indexes to measure efficiency changes over the specified period. They found that the healthcare system in Poland belonged to the most efficient within the compared countries, although the more indepth analysis showed some insufficiencies and fluctuations. In the Czech Republic, we can regard the development of efficiency as stable. In the case of Hungary, we can see a significant improvement, while Slovakia remained at shallow positions during the whole period. Grausová et al. (2015) also realised the analysis on the national level. They analysed the change of the efficiency of healthcare systems after the split of Czechoslovakia relatively to other European countries. Malmquist index was used to evaluate efficiency changes over the period 1995-2012. According to the results of the study, in Slovakia and the Czech Republic, the Malmquist index has fallen between the beginning and the end of the analysed period. They also found that the changes in health expenditures in both countries strongly influenced the Malmquist index, which underlines the importance of optimisation of health expenditures and their structure.

Medeiros and Schwierz (2015) estimated the relative efficiency of healthcare systems across all EU countries. They applied a comprehensive battery of models with different combinations of input and output variables. Outputs were the commonly reported health outcomes (e.g. life expectancy, healthy life expectancy, amenable mortality rate). Inputs included expenditure on healthcare, physical inputs and environmental variables. Notably, the Belgium, Cyprus, Spain, France, Italy, Netherlands and Sweden scored among the top seven performers in most of the models.

Traditional DEA models estimate a healthcare system as a black box while computing efficiency based on a set of inputs and outputs. It makes it difficult to differentiate the efficiency of various components of a healthcare system. Therefore, Tone and Tsutsui (2009); Kawaguchi et al. (2014) and Ozcan and Khushalani (2017) started to apply the network and dynamic DEA models.

Tone and Tsutsui (2009) present new types of DNDEA models, taking into account the internal or linking structure of DMUs. The DNDEA model can evaluate the overall efficiency, dynamic change in the periodic efficiency and dynamic change in the divisional efficiency. According to Ozcan and Khushalani (2017), in the healthcare sector, the advantage of DNDEA model is that it assesses efficiency separately in public health and also medical care sub-division. DMUs have carryover variables that take into account a positive or negative factor in the previous period.

Kawaguchi et al. (2014) wanted to perform an interim evaluation of the policy effect of the current reform of Japan's municipal hospitals. They focused on efficiency improvements both within hospitals and within two separate internal hospital organisations. Hospitals had two heterogeneous internal organisations: the medical examination division and administration division. The administration division carried out business management, and the medical division provided medical care services. They employed DNDEA model to estimate the dynamic change in efficiency from 2007 to 2009. They found out that the average 
efficiency of administration division decreased, while in the case of the medical division increased. Despite the reform policy, they failed to find any significant improvement in efficiency. Thus there were no positive policy effects despite the increased financial support from the central government.

\section{MATERIALS AND METHODS}

Consider $n$ DMUs $(j=1, \ldots, n)$, which consist of $K$ sub-divisions $(k=1, \ldots, K)$ over $T$ time periods $(t=1, \ldots, T)$. The number of inputs and outputs to sub-division $k$ represent $m_{k}$ and $r_{k}$, respectively. We denote the link leading from sub-division $k$ to sub-division $h$ by $(k, h)$ and the set of links by $L$. As mentioned by Cooper et al. (2007), we can define the observed data as follows:

- The set $\left\{X_{i j k}^{t} \in \mathrm{R}_{+}\right\}\left(i=1, \ldots, m_{k} ; j=1, \ldots, n ; k=1, \ldots, K\right.$; $t=1, \ldots, T$ ) represents input resource $i$ to $\mathrm{DMU}_{j}$ for sub-division $k$ in the period $t$.

- The set $\left\{y_{i j k}^{t} \in \mathrm{R}_{+}\right\}\left(i=1, \ldots, r_{k} ; j=1, \ldots, n ; k=1, \ldots, K\right.$; $t=1, \ldots, T$ ) represents output product i from DMUj for sub-division $\mathrm{k}$ in period $\mathrm{t}$. If some outputs are undesirable, we consider them as inputs to subdivision $k$.

- The set $\left\{z_{j(k h) l}^{t} \in \mathrm{R}_{+}\right\}\left(j=1, \ldots, n ; l=1, \ldots, L_{k h} ; t=1, \ldots, T\right)$ defines the linking intermediate products of DMU from sub-division $k$ to sub-division $h$ in period $t$. Then $L_{k h}$ is the number of items in links from $k$ to $h$.

- The set $\left\{z_{j k_{l}}^{(t,+1)} \in R_{+}\right\}\left(j=1, \ldots, n ; l=1, \ldots, L_{k} ; k=1, \ldots, K\right.$; $t=1, \ldots, T-1)$ represents carry-over of $\mathrm{DMU}_{j}$, subdivision $k$, from period $t$ to period $t+1$. Then $L_{k}$ is the number of items in the carry-over from subdivision $k$.

According to Cooper et al. (2007), we can express the objective function for the overall efficiency in the input-oriented model as follows (1). Where, $W^{t}(t=1, \ldots, T)$ represents the weight to period $t$ and $w^{k}$ represents the weight to sub-division $k$, represents the number of "as input" link from sub-division $k$, nbad $_{k}$, indicates the number of undesirable (bad) carry-overs for each sub-division $k, \boldsymbol{s}_{k o}^{t-}$ represents input slacks, $s_{o(k h) i n}^{t} \in R^{L_{(k h) i n}}$ represents slacks in case of the linking activities, and $s_{o k, b a d}^{(t, t+1)}$ denotes slacks, namely, carry-over excess (for detail specification see Cooper et al., 2007). These weights satisfy the condition $\sum_{t=1}^{T} W^{t}=1, \sum_{k=1}^{K} w^{k}=1, W^{t} \geq 0(\forall t), w^{k} \geq 0$ $(\forall k)$. They are supplied exogenously.

We can define the period efficiency in the inputoriented model as follows (2). Where variables on the right side of the equation indicate optimal values for the overall efficiency $\theta_{0}^{*}$.

We can define the divisional efficiency in the input-oriented model as follows (3).

Finally, we can determine the period-divisional efficiency in the input-oriented model as follows (4).

For evaluation of the healthcare system, we use the dynamic network DEA model. The model used in this study considers a selected European Union country's healthcare system as DMU (see Fig. 1). We assume that the healthcare system includes continuity between the public health system (population-based services) and the medical care system (provided to individual patients). According to Woolf and Aron (2013), both systems are equally essential components of a healthcare system, and therefore the same weights are assigned to both sub-divisions.

The inputs (I) to the public health sub-division include non-medical determinants of health outcomes beyond the control of medical care subdivision. These lifestyle inputs make a significant contribution to individual health outcomes. The limitation is that their control and regulation is usually a function of the public health department of the country (e.g. legislation and health education efforts related to smoking and alcohol consumption). According to Ozcan and Khushalani (2016) and Behr and Theune (2017) as inputs to public health sub-division, we include alcohol consumption and tobacco consumption. Preventive services such as immunisation and screening of chronic disorders like breast and cervical cancer affect the quality of the medical care services. However, they are usually under the supervision of the public health departments of most nations. Therefore, we include

$$
\begin{aligned}
& \theta_{o}^{*}=\min \sum_{t=1}^{T} W^{t}\left[\sum_{k=1}^{K} w^{k}\left[1-\frac{1}{m_{k}+\operatorname{linkin}_{k}+\operatorname{nbad}_{k}}\left(\sum_{i=1}^{m_{k}} \frac{s_{i o k}^{t-}}{x_{i o k}^{t}}+\sum_{(k h)_{l=1}}^{\operatorname{linkkn}_{k}} \frac{S_{o(k h)_{l} \text { in }}^{t}}{Z_{o(k h)_{l} i n}^{t}}+\sum_{k_{l}=1}^{n b a d_{k}} \frac{S_{o k k b a d}^{(t, t+1)}}{Z_{o k l b a d}^{(t, t+1)}}\right)\right]\right] \\
& \tau_{o}^{t^{*}}=\sum_{k=1}^{K} w^{k}\left[1-\frac{1}{m_{k}+\operatorname{linkin}_{k}+\operatorname{nbad}_{k}}\left(\sum_{i=1}^{m_{k}} \frac{S_{i o k}^{t-}}{x_{i o k}^{t}}+\sum_{(k h)_{l=1}}^{l i n k n_{k}} \frac{S_{o(k h)_{l} i n}^{t}}{Z_{o(k h)_{l} i n}^{t}}+\sum_{k_{l}=1}^{n b a d_{k}} \frac{S_{o k \text { klbad }}^{(t, t+1)}}{Z_{o k l b a d}^{(t, t+1)}}\right)\right],(t=1, \ldots, T) \\
& \delta_{o k}^{*}=\sum_{t=1}^{T} W^{t}\left[1-\frac{1}{m_{k}+\operatorname{linkin}_{k}+\operatorname{nbad}_{k}}\left(\sum_{i=1}^{m_{k}} \frac{s_{i o k}^{t-}}{X_{i o k}^{t}}+\sum_{(k h)_{l=1}}^{\operatorname{linkin}_{k}} \frac{S_{o(k h)_{l} i n}^{t}}{Z_{o(k h)_{l} i n}^{t}}+\sum_{k_{l}=1}^{n b a d_{k}} \frac{S_{o k b l b a d}^{(t, t+1)}}{Z_{o k k b a d}^{(t, t+1)}}\right)\right],(k=1, \ldots, K) \\
& \rho_{o k}^{t^{*}}=1-\frac{1}{m_{k}+\operatorname{linkin}_{k}+n b a d_{k}}\left(\sum_{i=1}^{m_{k}} \frac{S_{i o k}^{t-}}{X_{i o k}^{t}}+\sum_{(k)_{l=1}}^{\operatorname{linkin}_{k}} \frac{S_{o(k h)_{l} i n}^{t}}{Z_{o(k h)_{l} i n}^{t}}+\sum_{k_{l}=1}^{n b a d_{k}} \frac{S_{S_{o k l b a d}}^{(t, t+1)}}{Z_{o k l b a d}^{(t, t+1)}}\right),(k=1, \ldots, K ; t=1, \ldots, T)
\end{aligned}
$$




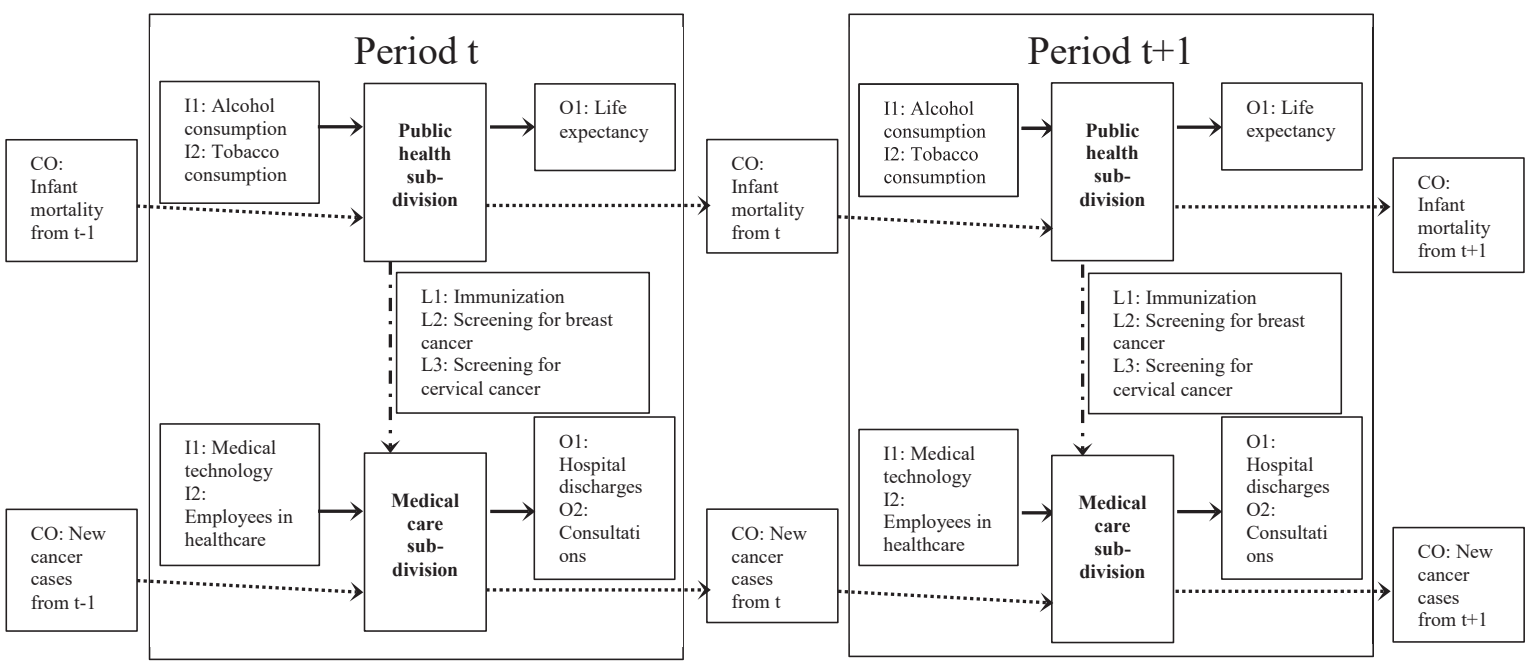

1: Dynamic network DEA model

Source: Prepared by authors based on Ozcan (2014)

them as links (L) from the public health sub-division to the medical care sub-division. These variables represent good links to the medical care subdivision as they reduce the disease burden on the medical care sub-division. The output $(\mathrm{O})$ from the public health sub-division includes life expectancy.

In our study, we apply the input-oriented model to measure the efficiency of the healthcare system, as we aim to minimise the level of inputs (alcohol and tobacco consumption) to obtain a given level of output (life expectancy). In other words, our goal is to see how a country should set its inputs effectively to reach given levels of output variables, namely the life expectancy. Since we assume that the country is not able to increase the output by one-time adjustment of inputs, but its level is given, we decided to use input-oriented models. We will, therefore, examine what should be the optimum level of public health inputs that correspond to life expectancy. In the field of public health, we also include a carry-over (CO) variable. It means a variable transmitted over time. In this case, such a variable is an indicator of infant mortality. This carry-over variable can affect the efficiency of a public health sub-division negatively, but most likely not immediately in a given period, but its impact on the efficiency will be reflected only after some time delay. The infant mortality indicator has an adverse effect on the level of healthcare in a given country. At the same time, the rising values of this indicator also have a negative impact on the overall efficiency of healthcare in the country.

The inputs to the medical care sub-division include a total number of medical technology per million inhabitants and total employment in the healthcare sector in the country per 1000 inhabitants (Retzlaff-Roberts et al., 2004; Pilyavsky and Staat, 2008). Outputs from the medical care sub-division include information about inpatient discharges and outpatient consultation (Ozcan,
2014; Kawaguchi et al., 2014). In this division, we have chosen the indicator of new cancer cases as a carry-over variable, since the adverse effect of this indicator is longer as we talk about chronic illness, the consequences of which are perceived over a more extended period.

\section{RESULTS AND DISCUSSION}

We collect the data from the OECD database (OECD, 2018) for the years 2008 and 2016, as the dataset for 2017 was not available. We include data from selected $23 \mathrm{EU}$ countries as not all EU countries are member states of OECD. That is why Bulgaria, Croatia, Cyprus, Malta, and Romania, were excluded from the sample. Descriptive statistics and definitions for all variables used in DNDEA model are presented in Tab. I.

The efficiency was calculated by mathematical program DEA Solver Pro 13. We decide to apply the model under the assumption of constant returns to scale as the number of analysed countries is relatively low compared to the number of input and output variables. Although some authors (e.g. RetzlaffRoberts et al., 2004; Hadad et al., 2013; Medeiros and Schwierz, 2015) say that it is more appropriate to consider variable returns as this assumptio takes into account the existence of imperfect competition. According to these authors, we could not assume that the healthcare sectors have the same (or very similar) size and we could not assume that there are proportionate changes between input and output variables, which is a condition in case of the constant returns to scale assumption. Also, Sendek et al. (2015) pointed to the fact, that we could not expect that the increase in bed capacities or of any other input necessarily lead to the same increase of hospitalisation and outpatient services, which could be considered as relatively stable in the region during the analysed period. 
I: Definitions and descriptive statistics of variables

\begin{tabular}{|c|c|c|c|}
\hline Variable & Definition & $\begin{array}{l}\text { Average/Min/Max } \\
\text { (2008) }\end{array}$ & $\begin{array}{l}\text { Average/Min/Max } \\
\text { (2016) }\end{array}$ \\
\hline \multicolumn{4}{|c|}{ PUBLIC HEALTH SUB-DIVISION } \\
\hline \multicolumn{4}{|c|}{ Inputs } \\
\hline Alcohol consumption & $\begin{array}{l}\text { Annual adult alcohol consumption of pure } \\
\text { alcohol in litres per capita }\end{array}$ & $11.10 / 6.80 / 14.20$ & $10.01 / 6.50 / 13.20$ \\
\hline Tobacco consumption & $\begin{array}{l}\text { Percentage of the people aged } 15 \text { years and } \\
\text { over who are reporting to smoke every day }\end{array}$ & $23.22 / 14.60 / 39.70$ & $19.15 / 7.60 / 27.30$ \\
\hline \multicolumn{4}{|c|}{ Outputs } \\
\hline Life expectancy & $\begin{array}{l}\text { How many years, on average, a newborn can } \\
\text { expect to live, if current death rates do not } \\
\text { change }\end{array}$ & $78.49 / 71.80 / 81.60$ & $80.33 / 74.70 / 83.40$ \\
\hline \multicolumn{4}{|c|}{ Carry-over: Bad } \\
\hline Infant mortality & $\begin{array}{l}\text { Number of deaths of children up to one year } \\
\text { per } 1000 \text { live births }\end{array}$ & $3.84 / 1.80 / 6.60$ & $3.33 / 1.90 / 5.40$ \\
\hline \multicolumn{4}{|c|}{ Links to medical care sub-division } \\
\hline Immunisation & $\begin{array}{l}\text { Percentage of children under 1-year-old } \\
\text { who received three doses of the combined } \\
\text { Diphtheria-Tetanus-Pertussis vaccine }\end{array}$ & $96.13 / 83.00 / 99.00$ & $95.61 / 87.00 / 99.00$ \\
\hline Screening-breast cancer & $\begin{array}{l}\text { Percentage of females aged } 50-69 \text { who } \\
\text { received bilateral mammography within the } \\
\text { past two years }\end{array}$ & $61.89 / 19.40 / 89.70$ & $63.52 / 27.40 / 90.40$ \\
\hline $\begin{array}{l}\text { Screening-cervical } \\
\text { cancer }\end{array}$ & $\begin{array}{l}\text { Percentage of females aged 20-69 who } \\
\text { received cervical cancer screening in the past } \\
\text { three years }\end{array}$ & $61.40 / 14.90 / 82.30$ & $63.82 / 25.20 / 86.60$ \\
\hline \multicolumn{4}{|c|}{ MEDICAL CARE SUB-DIVISION } \\
\hline \multicolumn{4}{|c|}{ Inputs } \\
\hline Medical Technology & $\begin{array}{l}\text { Computed Tomography scanners per million } \\
\text { inhabitants }\end{array}$ & 18.14 / 7.07 / 31.15 & 22.04 / 8.86 / 39.11 \\
\hline $\begin{array}{l}\text { Employment in } \\
\text { healthcare }\end{array}$ & $\begin{array}{l}\text { Persons (nurses and physicians) working in } \\
\text { the healthcare sector per } 1000 \text { inhabitants }\end{array}$ & $11.59 / 7.35 / 18.39$ & $12.52 / 7.58 / 20.56$ \\
\hline \multicolumn{4}{|c|}{ Outputs } \\
\hline Inpatient discharges & $\begin{array}{l}\text { Number of inpatient discharges per } 100000 \\
\text { inhabitants }\end{array}$ & 17842 / 11085 / 28114 & $17155 / 10926 / 25685$ \\
\hline Outpatient consultations & Number of outpatient consultation per capita & $6.59 / 2.90 / 12.10$ & $6.88 / 2.80 / 11.50$ \\
\hline \multicolumn{4}{|c|}{ Carry-over: Bad } \\
\hline New cancer cases & $\begin{array}{l}\text { The number of new cancer cases per } 100000 \\
\text { inhabitants }\end{array}$ & 264.26 / 162 / 321.10 & 271.82 / 163 / 338.10 \\
\hline
\end{tabular}

Source: Prepared by authors

On the other hand, Jacobs et al. (2006) pointed to the fact, that in the healthcare sector the input and output variables often have the form of ratios rather than absolute numbers (e.g. mortality rate, nurses per occupied bed, discharge rates). The application of such data automatically implies and assumption of constant returns to scale because the creation of the ratios removes any information about the size of the organisation. It encourages us to present the results of the input-oriented DNDEA under the assumption of constant returns to scale.
We present the efficiency scores for the public health sub-division, medical care sub-division and overall healthcare system for selected European Union countries in the next Tab. II. The average overall efficiency was 0.9198 in 2008. Thirteen countries have achieved a higher level of efficiency compared to the average in 2008. On the other hand, ten countries have achieved a lower level of efficiency compared to the average in 2008. In 2016 the average overall efficiency was 0.9362, where fourteen countries have achieved a higher level of efficiency compared to the average in 2016, and nine 
II: Efficiency scores for selected EU countries

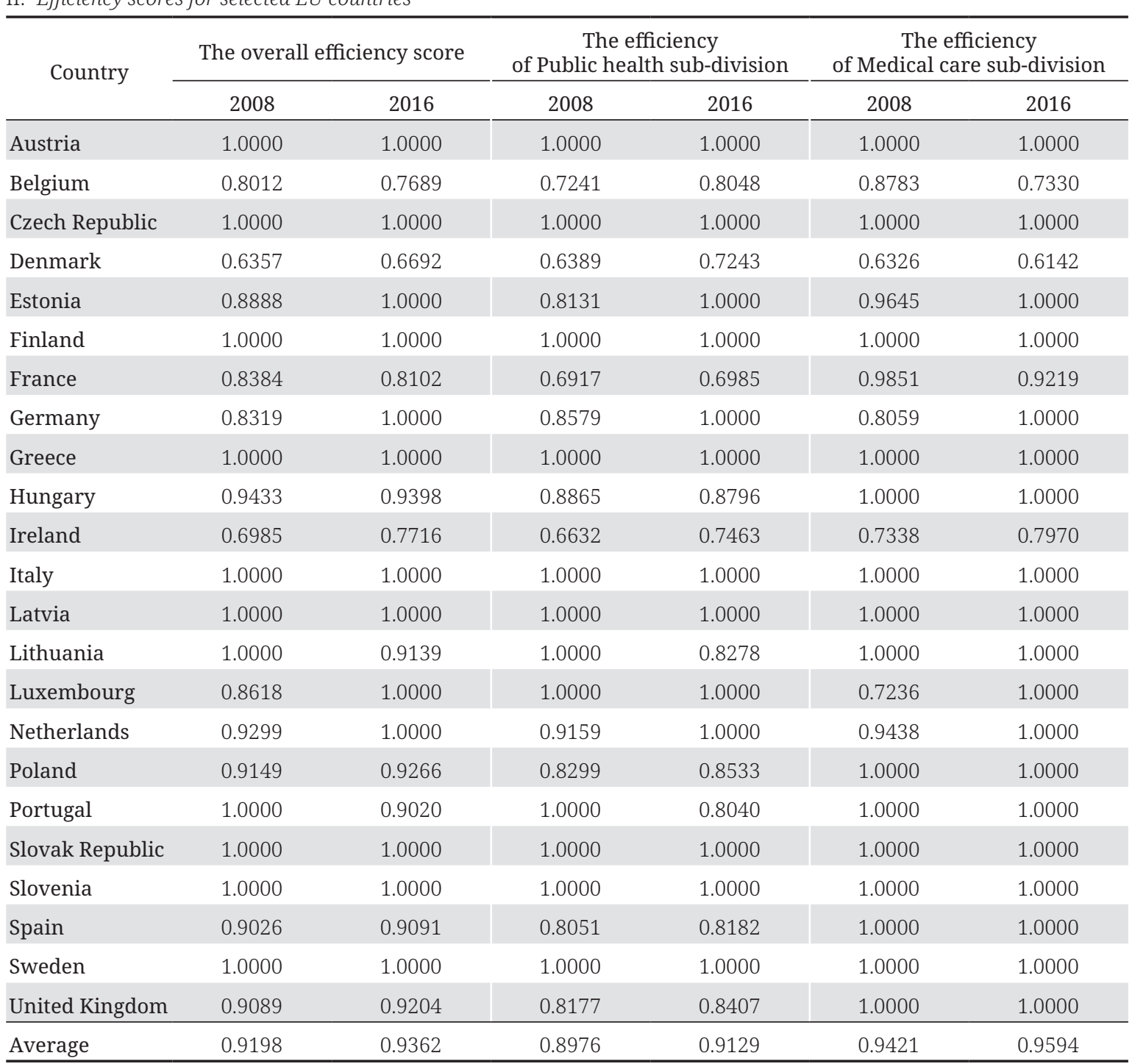

Source: Prepared by authors

countries have achieved a lower level of efficiency compared to the average in 2016. According to the achieved score, we can mark as efficient in both years: Austria, Czech Republic, Finland, Greece, Italy, Latvia, Slovak Republic, Slovenia and Sweden. The favourable development in these countries could be influenced by healthcare reforms which were taken in specified countries during the years 2000-2012. According to Ozcan and Khushalani (2017), countries like Austria, Denmark, Estonia, Germany, Netherlands, Portugal, and the Slovak Republic took the reforms. For example, Denmark in 2007 centralised and modernised the hospital sector, increased the role of municipalities in providing healthcare, improved coordination across different levels of the public sector and policy areas. The modernisation in the hospital sector and reforms in legislation had a positive impact on the efficiency within public health sub-division as well as within medical care sub-division. In the case of
Slovakia, the process of decentralisation of hospitals as well as other reforms which take part since 2005 had a positive impact on the efficiency in both years within the analysed group of countries under the applied criteria.

When we look at the efficiencies of sub-divisions, we can see that the average efficiency of public health sub-division was 0.8976 in 2008 and 0.9129 in 2016. In 2016 thirteen countries achieved a higher level of efficiency compared to the average and ten countries have achieved a lower level of efficiency compared to the average in 2016. In the case of the medical care sub-division, nineteen countries achieved a higher level of efficiency compared to the average in 2016 (0.9594) and only four countries have achieved a lower level of efficiency compared to the average. When we compare the level of public health sub-division efficiency and medical care sub-division efficiency, we can see that the efficiency of the public health 
sub-division in 2016 was higher than medical care sub-division only in Belgium and Denmark. In the case of France, Hungary, Ireland, Lithuania, Poland, Portugal, Spain and the United Kingdom, the medical sub-division was more efficient. Comparing the results, we can say that the countries tend to be more efficient within the medical care sub-division. Both divisions were efficient in the case of Austria, Czech Republic, Estonia, Finland, Germany, Greece, Italy, Latvia, Luxembourg, Netherlands, Slovak Republic, Slovenia and Sweden. We have also calculated the correlation between sub-divisions. The value of the Pearson correlation coefficient between these values was 0.57 , which, according to Cohen (1988) suggests a large correlation between the efficiencies in both areas.

As mentioned by some authors (e.g. Bohm et al., 2013; Ozcan and Khushalani, 2017 or Gaeta et al., 2017) health systems in the European Union can be managed differently according to models of service delivery, financing, and economic policies. They defined two basic systems: national health service model (also referred to as "Beveridge" systems) and social insurance model (also referred to as "Bismarck" systems) concerning the role of the state as financier and owner of facilities. The Beveridge model where healthcare is provided and financed by the government through public taxes. In Europe Union, this model is adopted by Denmark, Finland, Greece, Ireland, Italy, Latvia, Poland, Portugal, Spain, Sweden and the United Kingdom. On the other hand, in the Bismarck model, the financial funding of the healthcare system is granted through compulsory social security contributions by employers and employees. No-profit agencies exert the management of the funds. The state provides healthcare coverage to those who are not registered in the employment insurance fund. This model is adopted in Austria, Belgium, Czech Republic, Estonia, France, Germany, Hungary, Lithuania, Luxembourg, Netherlands, Romania, Slovak Republic, and Slovenia. According to this classification, we can see that in our study in 2016, the countries with the Bismarck model tend to be more efficient. The average overall efficiency in countries with Bismarck model was 0.9527, while in countries with the Beveridge model was 0.9181. In public health sub-division, the average efficiency in countries with Bismarck model was 0.9342, while in countries with the Beveridge model was 0.8897. In medical care sub-division, the average efficiency in countries with Bismarck model was 0.9712, while in countries with the Beveridge model was 0.9465

The next part of the paper analyses changes in the efficiencies using the Malmquist index. The overall Malmquist index (MI) can be decomposed in frontier shift (FS) effect and catch-up (CU) effect. The frontier shift effect represents an improvement in efficiency due to the innovation, while the catch-up effect represents an improvement in efficiency due to improved operations and management of healthcare system (or management of public health sub-division or medical care sub-division) and also optimisation in terms of size. While the MI, FS, and CU above 1 indicate the improvement between periods, the values below 1 indicate worsening in the efficiency. The total improvement, respectively, the deterioration can be calculated as the difference between the index value and the number 1 . In percentage form, the difference is multiplied by 100 .

In the previous Tab. III, we can see the result of overall Malmquist index, frontier shift effect (FS) and catch up effect (CU) for EU countries. The average progress of $2.5 \%$ in the total factor productivity (MI) was recorded. The progress in the overall total factor productivity index was caused by the $5.01 \%$ growth in the relative technical efficiency (catch up effect) and positive innovation effect (1.14\%) which led to the shift of production possibility frontier. The overall progress was

III: Overall Malmquist index and its components for selected EU countries

\begin{tabular}{|c|c|c|c|}
\hline Country & FS & $\mathrm{CU}$ & MI \\
\hline Austria & 0.9714 & 1.0000 & 0.9856 \\
\hline Belgium & 0.9533 & 0.9275 & 0.9403 \\
\hline Czech Republic & 0.9495 & 1.0000 & 0.9744 \\
\hline Denmark & 0.9144 & 1.1008 & 1.0033 \\
\hline Estonia & 1.0353 & 1.2752 & 1.1490 \\
\hline Finland & 1.0060 & 1.0000 & 1.0030 \\
\hline France & 0.9589 & 0.9450 & 0.9519 \\
\hline Germany & 0.8302 & 1.4463 & 1.0957 \\
\hline Greece & 1.1434 & 1.0000 & 1.0693 \\
\hline Hungary & 1.0569 & 0.9921 & 1.0240 \\
\hline Ireland & 0.9582 & 1.2222 & 1.0822 \\
\hline Italy & 0.8482 & 1.0000 & 0.9210 \\
\hline Latvia & 1.0070 & 1.0000 & 1.0035 \\
\hline Lithuania & 1.2172 & 0.8278 & 1.0038 \\
\hline Luxembourg & 0.8521 & 1.3820 & 1.0852 \\
\hline Netherlands & 1.3050 & 1.1568 & 1.2287 \\
\hline Poland & 1.1487 & 1.0281 & 1.0867 \\
\hline Portugal & 1.0612 & 0.8040 & 0.9237 \\
\hline Slovak Republic & 1.0104 & 1.0000 & 1.0052 \\
\hline Slovenia & 0.9982 & 1.0000 & 0.9991 \\
\hline Spain & 1.0835 & 1.0162 & 1.0493 \\
\hline Sweden & 0.9363 & 1.0000 & 0.9676 \\
\hline United Kingdom & 1.0159 & 1.0281 & 1.0220 \\
\hline Average & 1.0114 & 1.0501 & 1.0250 \\
\hline
\end{tabular}

Source: Prepared by authors 
positively influenced by the progress of $15.58 \%$ in the case of the public health sub-division and by the deterioration of $8.67 \%$ in medical care sub-division. The progress in the total factor productivity index in case of public health sub-division was caused by the $2.45 \%$ growth in the relative technical efficiency and positive innovation effect (13.04\%). In the case of medical care sub-division, the deterioration was caused by the growth in the relative technical efficiency by $2.38 \%$ and the adverse innovation effect (10.56\%). The frontier shift effect representing the impact of innovation was positive only within the public health sub-division. However, the source for this effect can be latent and of any technological change or progress, macroeconomic development, and government regulations. All these issues, together with information technologies, influenced the public health sub-divisions ability to offer more appropriate services, enabling them to take their services closer to patients and so increase their efficiency. The catch-up effect was positive in case of both sub-divisions, which represents an improvement in technical efficiency due to improved operations and management of healthcare systems and optimisation of their optimal size.

Overall, 15 countries achieved an improvement $(\mathrm{MI}>1)$ in performance: Denmark, Estonia, Finland, Germany, Greece, Hungary, Ireland, Latvia, Lithuania, Luxembourg, Netherland, Poland, Slovak Republic, Spain and the United Kingdom. On the other hand, Austria, Belgium, Czech Republic, France, Italy, Portugal, Slovenia and Sweden recorded a decline $(\mathrm{MI}<1)$ over the reporting period. The highest growth can be seen in the case of Netherland, which achieved the efficiency improvement of $22.87 \%$ over the analysed period. On the other hand, Italy achieved the highest deterioration, of $7.9 \%$. The value of the Malmquist index indicates technological deterioration. The decomposition of MI indicates that the adverse innovation effect caused this deterioration in both sub-divisions. The catch-up effect in both sub-divisions is always equal to one indicating no change from the technical efficiency point of view. Within the analysed sample, Italy was able to be efficient. However, the lack of technological progress, macroeconomic development and lack of government regulations in the healthcare sector can lead to the deterioration of the technical efficiency in the future.

The graph (Fig. 2) shows a comparison of the Malmquist indexes in the public health and medical care sub-division over the analysed period. The graph can be divided into four quadrants based on growth or decline in performance in sub-divisions. The classification of countries within the DNDEA model narrows to three areas, the second, third and fourth quadrant. The Netherlands, Germany and Luxembourg achieved efficiency growth in both sub-divisions, therefore, could be seen within the second quadrant. The countries Austria, Belgium, the Czech Republic, Denmark, Estonia, Finland, France, Greece, Hungary, Ireland, Latvia, Lithuania, Poland, Slovak Republic, Slovenia, Spain, Sweden and the United Kingdom could be seen within the fourth quadrant. The value of overall MI indicated technological progress in the case of Denmark,

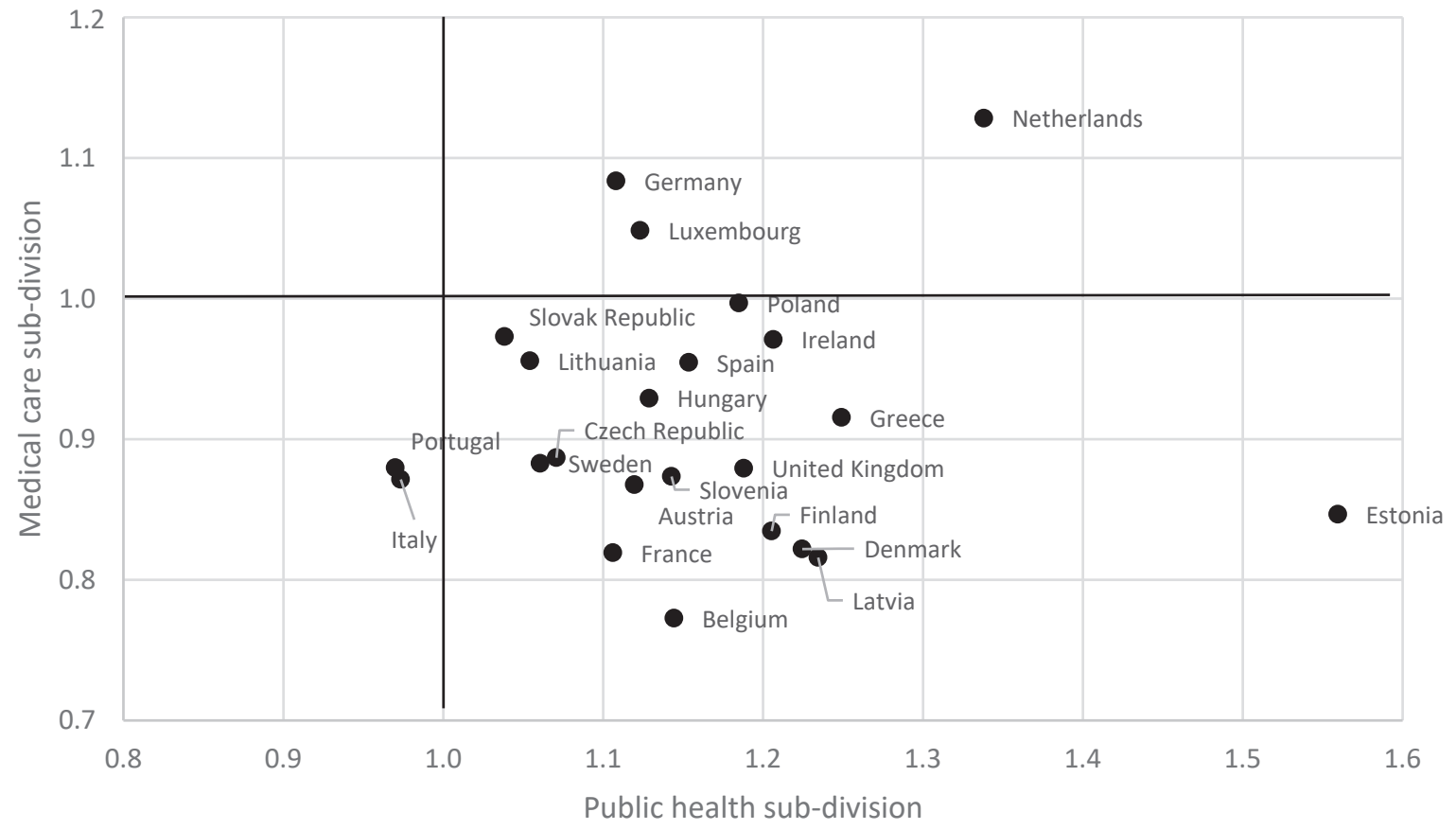

2: Malmquist index in sub-divisions Source: Prepared by authors 
Estonia, Finland, Greece, Hungary, Ireland, Latvia, Lithuania, Poland the Slovak Republic, Spain and the United Kingdom, mainly due to technological progress within the public health sub-division caused by innovation effect. In the case of Austria, Belgium, the Czech Republic, France, Slovenia and
Sweden, the overall total factor productivity (MI) decreased, mainly due to the adverse innovation effect in medical care sub-division. The decline in the total factor productivity index in case of public health sub-division can be seen only in the case of two countries: Portugal and Italy (third quadrant).

\section{CONCLUSION}

In this paper, we tried to present the issue of efficiency of the service sector with a focus on the healthcare sector. Based on the study of relevant literature, we can say that this topic is still actual. The interest in this topic can also be seen in the design and correct setting of framework policies. The primary objective of this study was to evaluate the technical efficiency in the healthcare sector in selected EU countries.

In the paper, we introduced the methodology of our research. We applied dynamic and network DEA model, which eliminated the imperfections of the basic models and allowed to evaluate efficiency across multiple divisions over a more extended period. The DNDEA model consisted of a selection of inputs and outputs for two sub-divisions: the public health sub-division and the medical care subdivision. Within these two sub-divisions, we estimated efficiency based on 12 variables. We analysed the efficiency of healthcare systems in 23 EU countries in 2008 and 2016. The results pointed to the improvement in healthcare systems in analysed countries, which was confirmed by overall Malmquist index (1.025) indicating a shift of analysed countries to the efficiency frontier mainly due to total factor productivity improvement in public health sub-division by $15.58 \%$.

The result indicated that countries that were undergoing reform had shown a more significant increase in the efficiency of the overall healthcare system and both sub-divisions. The Malmquist index showed an improvement in the overall healthcare system over time in the case of 15 countries. This growth was pushed by higher progress in the public health sub-division as compared to the medical care sub-division. Thus, the efficiency of the public health sub-division played a crucial role in the overall efficiency of the healthcare system and therefore, could be a priority for nations.

Let us remind that the main limitations not only of our work but also of several studies, where the decision-making units are the healthcare systems of several countries, lie precisely in the availability of data in individual world databases. The inconsistency in the publication and updating of the data partly compromises the level of results. It should be emphasised that in the case of assessing the efficiency of healthcare is necessary to include between input and output variables not only data that reflect the technical aspect of the healthcare system, but also the data that reflect lifestyle of the population, environmental and socio-economic factors. As the countries are required to provide quality public services while minimising public expenditure, it is also necessary to study the relationship between healthcare system efficiency and public expenditure in this sector. Examination of such associations could lead to more effective health policies, showing in each country whether the financial and investment resources in the related budget chapters are beneficial, appropriately and efficiently allocated and there is no excessive waste of resources.

Acknowledgements

The Slovak Scientific Grant Agency supported this work as part of the research project VEGA 1/0794/18.

\section{REFERENCES}

ADANG, E. M. and BORM, G. F. 2007. Is there an association between economic performance and public satisfaction in health care? The European Journal of Health Economics, 8(3): 279-285.

ADLER, N. and YAZHEMSKY, E. 2010. Improving discrimination in data envelopment analysis: PCA-DEA or variable selection. European Journal of Operational Research, 202(1): 273-284.

BANKER, R. D., CHARNES, A. and COOPER, W. W. 1984. Some models for estimating technical and scale inefficiencies in data envelopment analysis. Management Science, 30(9): 1078-1092.

BEHR, A. and THEUNE, K. 2017. Health System Efficiency: A Fragmented Picture Based on OECD Data. Pharmaco Economics, 1(3): 203-221.

BOHM, K., SCHMID, A., GOTZE, R., LANDWEHR, C. and ROTHGANG, H. 2013. Five types of OECD healthcare systems: empirical results of a deductive classification. Health Policy, 113(3): 258-269. 
CANTOR, V. J. M. and POH, K. L. 2018. Integrated Analysis of Healthcare Efficiency: A Systematic Review. Journal of Medical Systems, 42(8): 8-23.

CHARNES, A., COOPER, W. W. and RHODES, E. 1978. Measuring the efficiency of decision-making units. European Journal of Operational Research, 2(6): 429-444.

COHEN, J. 1988. Statistical Power Analysis for the Behavioral Sciences. $2^{\text {nd }}$ Edition. Routledge.

COOPER, W. W., SEIFORD, L. M. and TONE, K. 2007. Data Envelopment Analysis: A Comprehensive Text with Models, Applications, References and DEA-Solver Software ( $2^{\text {nd }}$ ed.). Springer.

DEBREU, G. and ARROW, K. J. 1954. The existence of an equilibrium for a competitive economy. Econometrica: Journal of the Econometric Society, 22(3): 265-290.

DYSON, R. G. and SHALE, E. 2010. Data envelopment analysis, operational research and uncertainty. Journal of the Operational Research Society, 61(1): 25-34.

FÄRE, R., GROSSKOPF, S., NORRIS, M. and ZHANG, Z. 1994. Productivity growth, technical progress, and efficiency change in industrialised countries. American Economic Review, 84(1): 66-83.

FARRELL, P. 1957. DEA in production center: An input-output mode. Journal of Econometrics, 3: 23-49.

GAETA, M., CAMPANELLA, F., CAPASSO, L., SCHIFINO, G. M., GENTILE, L., BANFI, G., PELLISERO, G. and RICCI, C. 2017. An overview of different health indicators used in the European Health Systems. Journal of Preventive Medicine and Hygiene, 58(2): 114-120.

GRAUSOVÁ, M., HUŽVÁR, M. and ŠTRANGFELDOVÁ, J. 2014. Healthcare Systems Efficiency in the Visegrád Group. In: Proceedings of the 17th International Scientific Conference on Applications of Mathematics and Statistics in Economics. Poland, 27-31 August 2014. Wrocław: Wydawnictwo Uniwersytetu Ekonomicznego we Wrocławiu, pp. 104-113.

GRAUSOVÁ, M., HUŽVÁR, M. and ŠTRANGFELDOVÁ, J. 2015. The efficiency of healthcare systems in the Czech Republic and Slovakia after the dissolution of Czechoslovakia. In: Proceedings of the $18^{\text {th }}$ International Scientific Conference on Applications of Mathematics and Statistics in Economics. University of Economics. Prague: Oeconomica Publishing House.

GROSSKOPF, S. and VALDMANIS, V. 1993. Evaluating hospital performance with case-mix adjusted outputs. Medical Care, 31(6): 525-532.

HADAD, S., HADAD, Y. and SIMON-TUVAL, T. 2013. Determinants of the healthcare system's efficiency in OECD countries. The European Journal of Health Economics, 14(2): 253-265.

KAWAGUCHI, H., TONE, K. and TSUTSUI, M. 2014. Estimation of the efficiency of Japanese hospitals using a dynamic and network data envelopment analysis model. Health Care Management Science, 17(2): 101-112.

KNEIP, A., SIMAR, L. and WILSON, P. 2008. Asymptotics and consistent bootstraps for DEA estimators in non-parametric frontier models. Econometric Theory, 24(6): 1663-1697.

KOUSMANEN, T. 2009. Data envelopment analysis with missing data. Journal of Operational Research Society, 60(12): 1767-1774.

MEDEIROS, J. and SCHWIERZ, C. 2015. Efficiency estimates of health care systems. No. 549. Directorate General Economic and Financial Affairs (DG ECFIN). European Commission.

MORITA, H. 2003. Analysis of economies of scope by data envelopment analysis: Comparison of efficient frontiers. International Transactions in Operational Research, 10(4): 393-402.

OECD. 2018. Health at a Glance 2017: OECD Indicators. OECD iLibrary. [Online]. Available at: http:// dx.doi.org/10.1787/health_glance-2017-en [Accessed: 2018, June 18].

OSEI, D., D'ALMEIDA, S. and GEORGE, M. O. 2005. Technical efficiency of public district hospitals and health centres in Ghana: A pilot study. Cost Effectiveness and Resource Allocation, 3(1): 9.

OZCAN, Y. A. 2014. Health care benchmarking and performance evaluation. An assessment using Data Envelopment Analysis. New York: Springer.

OZCAN, Y. A. and KHUSHALANI, J. 2017. Assessing the efficiency of public health and medical care provision in OECD countries after a decade of reform. Central European Journal of Operations Research, 25(2): 325-343.

PILYAVSKY, A. I. and STAAT, M. 2008. Efficiency and productivity change in Ukranian health care. Journal of Productivity Analysis, 29: 143-154.

RAMÍREZ-VALDIVIA, M. T., MATURANA, S. and SALVO-GARRIDO, S. 2011. A multiple stage approach for performance improvement of primary healthcare practice. Journal of Medical Systems, 35(5): 1015-1028.

RETZLAFF-ROBERTS, D., CHANG, C. F. and RUBIN, R. M. 2004. Technical efficiency in the use of health care resources: a comparison of OECD countries. Health policy, 69(1): 55-72.

SAMUT, P. K. and CAFRI, R. 2016. Analysis of the Efficiency Determinants of Health Systems in OECD Countries by DEA and Panel Tobit. Social Indicators Research, 129(1): 113-132. 
SENDEK, S., SVITÁLKOVÁ, Z. and ANGELOVIČOVÁ, K. 2015. Efficiency evaluation of hospitals in the environment of the Czech and Slovak Republic. Acta Universitatis Agriculturae et Silviculturae Mendelianae Brunensis, 63(6): 2109-2118.

STAŇKOVÁ, P. and PAPADAKI, Š. 2017. A comparison of the efficiency of hospitals in the individual regions of the Czech Republic. Scientific Papers of the University of Pardubice. Series D, Faculty of Economics \& Administration, 24(39): 200-210.

STEFKO, R., GAVUROVA, B. and KORONY, S. 2016. Efficiency measurement in healthcare work management using Malmquist indices. Polish Journal of Management Studies, 13(1): 168-180.

TONE, K. and TSUTSUI, M. 2009. Network DEA: A slacks-based measure approach. European Journal of Operational Research, 197(1): 243-252.

VAŇKOVÁ, I. and VRABKOVÁ, I. 2014. The factors influencing the economic efficiency of the hospital bed care in terms of regional allowance organisations. Review of Economic Perspectives, 14(3): 233248.

WOOLF, S. H. and ARON, L. 2013. US health in international perspective: shorter lives, poorer health. Report. Washington: The National Academies/Institute of Medicine.

ZHU, J. and COOK, W. D. 2007. Modelling data irregularities and structural complexities in Data Envelopment Analysis. New York: Springer.

Contact information

Kristína Kočišová: kristina.kocisova@tuke.sk Jakub Sopko: jakub.sopko@tuke.sk 